\title{
LUCRÉCIA, LUCRETIA E ARTEMÍSIA: A (DES)HONRA DE VIVER
}

\author{
Miriam de Paiva Vieira
}

Doutoranda em Literatura Comparada do Programa de Pós-Graduação em Estudos Literários /

UFMG

\section{RESUMO}

O objetivo deste ensaio é procurar evidências na maneira de lidar com a violação sexual das personagens protagonistas femininas do capítulo intitulado "Lucrézia”, do romance A paixão de Artemísia (2002), da escritora Susan Vreeland, do quadro Lucretia, da pintora italiana Artemísia Gentileschi (1621), e do poema narrativo O rapto de Lucrécia, de Shakespeare (1594).

\section{PALAVRAS-CHAVE}

Intermidialidade, literatura, pintura, Shakespeare

“A arte pode ajudar nessa mudança”. ${ }^{1}$

Gulnaz, uma jovem afegã condenada por adultério após ter sido estuprada pelo marido de sua prima, tem sido notícia por ter tido sua pena de 12 anos amenizada para três anos devido às repercussões do documentário In-Justice: the story of afghan women in Jail, encomendado pela União Europeia. Para ser perdoada e ter legitimada sua filha, que foi concebida pelo estupro, Gulnaz deverá se casar com o seu agressor. A advogada americana da garota ainda tem esperanças de mudar o desfecho do caso. Porém, se o agressor, que também está preso por crime de adultério, se sentir humilhado, poderá vir a violá-la novamente, ou mesmo matá-la, por uma questão de honra, de acordo com as tradições do país de leis islâmicas. Entretanto, de acordo com Luiz Flávio Gomes, jurista e cientista criminal brasileiro, praticamente oito mulheres são mortas por dia no Brasil devido à violência machista. Ele também alega que uma, em cada 10 mulheres, já foi estuprada na Noruega,

${ }^{1}$ VREELAND. A paixão de Artemísia, p. 228. 
Escandinávia, região reconhecida como exemplo de defesa e promoção dos direitos da mulher.

Um dos objetos de estudo de meu projeto de doutorado é o romance do tipo Künstlerroman, A paixão de Artemísia. O romance, mesclando realidade e ficção, conta a trajetória da pintora caravaggista Artemísia Gentileschi (1593-1652), que foi estuprada pelo seu tutor Agostino Tassi e depois torturada e humilhada durante o julgamento, segundo registros encontrados. ${ }^{2}$ Grande parte do processo de criação da protagonista acontece como uma catarse promovida pelos sentimentos contraditórios que ela sente em relação ao seu tutor, Agostino Tassi. Apesar de minha proposta ser um estudo do romance como obra intermidiática, e não uma leitura feminista da vida da artista dentro do romance, o estupro tem um papel fundamental na construção da trama e em suas relações intermidiáticas.

Considerando os casos de Gulnaz na realidade do século 21, e de Artemísia, na ficção, pergunto: como ficam as consequências acarretadas pelo estupro na vida da vítima? Alguma coisa mudou, na sociedade ocidental, nos últimos 400 anos? Para melhor compreender essas questões, ainda hoje tão melindrosas, buscarei “ouvir” evidências encontradas na maneira de lidar com a violação sexual das personagens protagonistas femininas do capítulo intitulado “Lucrézia”, do romance A paixão de Artemísia (2002) da autora americana Susan Vreeland, do quadro Lucretia (1621), da pintora italiana Artemísia Gentileschi, e do poema narrativo $O$ Rapto de Lucrécia (1594), de Shakespeare.

Na virada do século 17 (o poema foi escrito em 1594 na Inglaterra e o quadro pintado em 1621 na Itália), a palavra rape não era entendida somente como "violação sexual”, mas também como “abdução”, “rapto”. ${ }^{3}$ A palavra inglesa rape vem do latim, rapere ("pegar a presa”, “tomar à força”, “abduzir”). Até final do século 14 era raramente usada como “violação sexual”; a palavra usada para esse fim era stuprum (“desgraça”, “desonra”). Segundo o Dictionary.Com etimológico eletrônico, o substantivo com conotação de "violação sexual ou arrebatamento de uma mulher” em inglês foi registrado pela primeira vez em 1481, e o verbo com esse sentido data de 1577. De acordo com o Dicionário Houaiss da língua portuguesa, a palavra "estupro” significa somente “crime sexual”; já “rapto” tem como um de seus significados o “crime que consiste na subtração de mulher honesta, de um local para

${ }^{2}$ Esses registros foram reproduzidos em Artemisia Gentileschi. The image of the female Hero in Italian Baroque Art de Mary D. Garrard, professora de História da Arte na American University em Washigton D.C.

${ }^{3}$ BELSEY. Tarquin dispossessed: expropriation and consent, p. 55. 
outro, tendo em vista fins libidinosos, utilizando violência ou grave ameaça”. ${ }^{4}$ A tradução mais encontrada do título do poema para o português é $O$ rapto de Lucrécia. Entretanto, Solange Oliveira ${ }^{5}$ prefere enfatizar como o crime é visto hoje em dia.

O poema de Shakespeare foi publicado em 1594 como Lucrécia, e recebeu o título $O$ Rapto de Lucrécia em 1616. Suas fontes primárias seriam um trecho dos anais de Roma por Titus Livius e um episódio de Fasti de Ovídio, que contam o mito de Lucrécia, a esposa casta de Collatinus que se mata após ser estuprada por Sextus Tarquinios, filho do rei etrusco de Roma. O corpo da vítima é levado a público, causando uma rebelião e banimento do rei, o que resulta no fim da dinastia etrusca e instauração da República. O poema mantém a sequência dos eventos narrativos expandindo o material oferecido por suas fontes ${ }^{6}$ e acrescentando "nuances psicológicas ao perfil das personagens". ${ }^{7}$ Com os poemas dedicados ao conde de Southampton, Vênus e Adônis e O rapto de Lucrécia, Shakespeare “apostou alto para ser reconhecido como poeta pela sociedade refinada”" durante os anos em que os teatros de Londres estavam fechados para evitar o contágio da peste.

De acordo com a historiadora Mary Garrard, as leis da Roma antiga não distinguiam claramente a diferença entre estupro e adultério. Além disso, para os romanos, o suicídio não era um ato moralmente errado, mas uma escolha racional de pôr fim a uma vida de modo honrado. Portanto, o suicídio de Lucrécia após ser estuprada pode ser entendido, no contexto de sua época, como uma ação justificada e compatível aos conceitos romanos de virtude, tanto para homens quanto para mulheres. Lucrécia se matou de vergonha, preocupada mais com as consequências acarretadas para seu marido do que com a sua própria reputação.

Já na era cristã, a ação da virtuosa pagã, que prezava mais sua honra do que a própria vida, foi questionada. Na Idade Média, o mito de Lucrécia era considerado um modelo de castidade a inspirar as mulheres cristãs a preservar a virgindade. Em reação à onda de estupros de freiras durante o saque de Roma em 410 d.C., Santo Agostinho explorou as diferenças dos princípios romanos e cristãos de modo a justificar moralmente a escolha de essas freiras manterem suas vidas. Para ele, apesar de Lucrécia não ser adúltera, uma vez que

\footnotetext{
${ }^{4}$ HOUAISS; VILLAR. Dicionário Houaiss da língua portuguesa, p. 1611.

${ }^{5}$ OLIVEIRA. Contemporaneidade de Shakespeare: a violência contra a mulher no poema narrativo $O$ estupro de Lucrécia.

${ }^{6}$ BELSEY. Tarquin dispossessed: expropriation and consent, p. 59.

${ }^{7}$ OLIVEIRA. Contemporaneidade de Shakespeare: a violência contra a mulher no poema narrativo $O$ estupro de Lucrécia, p. 6.

${ }^{8}$ HONAN. Shakespeare: uma vida, p. 217.
} 
somente o seu corpo, e não sua mente, fora violentado, ela usurpou a lei de Deus cometendo o crime de tirar sua própria vida. Entretanto, escritores, tais como Dante, Boccaccio e Chaucer, escolheram ignorar as questões levantadas por Santo Agostinho, e perpetuar a imagem de Lucrécia como paradigma da castidade. No século 12, outros escritores, especialmente os ingleses, preferiram não evocar o mito a fim de evitar decisões errôneas a favor do suicídio. Alguns céticos não acreditavam totalmente na castidade de Lucrécia, particularmente na Itália renascentista. Nas dramatizações de Coluccio, Saletati e Matteo Bandello, por exemplo, Lucrécia admite ter sentido prazer, por ser de carne e osso, e prefere morrer por ter participado ativamente do ato. A partir da comédia La mandragola, de Machiavel, em que Lucrécia não é violentada, mas desfruta de seu amante, muitas releituras do mito tomam um tom cômico retratando uma Lucrécia promíscua. O mito foi também explorado por escritoras. Para a italiana Christine de Pizan (1364-1430), Lucrécia era um protótipo de integridade, afinal, o estupro aconteceu devido a tal característica e não devido a sua beleza. A também italiana Lucrezia Marinelli (1572-1653) preferiu, por sua vez, não incluir a mártir em seu completo tratado acerca das grandes e importantes figuras femininas da Antiguidade. No século 20, Simone de Beauvoir observou que o suicídio de Lucrécia só tem valor como um símbolo.

As consequências do estupro, sendo ele prazeroso ou não, são sempre as mesmas: o problema da gravidez e o da reputação. O ponto de vista masculino foca o que a mulher sente em relação ao ato de violência. Enquanto o ponto de vista feminino foca as mudanças permanentes que o ato acarreta, independentemente de o coito em si ser prazeroso ou doloroso, a mulher tem que lidar sozinha com consequências biológicas e sociais. ${ }^{9}$

No poema de Shakespeare, o ato de violência é promovido pela luxúria e orgulho de Tarquin; porém, logo após se satisfazer, ele parece já estar arrependido e quer saber como ela se sente. De acordo com os recortes a seguir, sua atitude confirma o padrão do olhar masculino sugerido por Garrard:

Ere he can see his own abomination. /While Lust is in his pride, no exclamation (...) The flesh being proud, Desire doth fight with Grace,/ For there it revels; and when that decays,/ The guilty rebel for remission prays. (...) Besides, /his soul's fair temple is defac'd;/ To whose weak ruins muster troops of cares,/ To ask the spotted princess how she fares. ${ }^{10}$

${ }^{9}$ GARRARD. Artemisia Gentileschi: the image of the female hero in Italian baroque art, p. 217-220.

10 “Antes que ele visse sua própria abominação./ Com a Luxúria em seu orgulho, sem exclamação/ O Desejo com graça luta, estando a carne orgulhosa,/ Pois lá regojiza; e quando este deteriora,/ O rebelde arrependido por seu perdão ora./ Além do mais, o templo honesto de sua alma está 
O poema continua contrastando as reações imediatas do agressor com as da vítima, que são as que me interessam. No trecho abaixo, Shakespeare mostra uma Lucrécia ciente das consequências sociais acarretadas pela violência sofrida, ou seja, em acordo com a premissa feminina de Garrard:

He like a thievest dog creeps sadly thence;/ She like a wearied lamb lies panting there;/ He scowls and hates himself for his offence;/ She, desperate, with her nails her flesh doth tear;/ He faintly flies, sneaking with guilty fear;/ She stays, exclaiming on the direful night;/ He runs, and chides his vanish'd, loath'd delight. (...) He thence departs a heavy convertite;/ She there remains a hopeless castaway;/ He in his speed looks for the morning light;/ She prays she never may behold the day,/ "For day", quoth she, 'night's scapes doth open lay,/ And my true eyes have never practis'd how/To cloak offences with a cunning brow. ${ }^{11}$

Lucrécia continua debatendo consigo mesma, como pode ser observado em várias estrofes do poema. Seus sentimentos oscilam entre culpa, raiva, dor e arrependimento. Ela pragueja contra seu agressor, contra a Oportunidade, o Tempo e a Noite. Suplica poder voltar no tempo e assim evitar sua tormenta. De acordo com Laura Stampler, ${ }^{12}$ Shakespeare dá espaço não somente para o sofrimento de Lucrécia, como nas suas fontes inspiradoras, mas também para a contemplação e entendimento do crime cometido contra ela. Lucrécia é capaz de encontrar sua voz como vítima e também como mulher, ou seja, uma maneira incomum de retratar o mito.

Na pintura, assim como na literatura, as representações renascentistas e barrocas de Lucrécia podem ser também divididas em grupos. No século 15, as telas retratam um exemplo de esposa virtuosa; o corpo aparece em um cenário arquitetônico suntuoso e cercado de

desfigurado;/ Para cujas frágeis ruínas reúne grande cuidado,/ Perguntando à princesa manchada pelo seu estado " (SHAKESPEARE. The rape of Lucrece. The Gutemberg Project, tradução nossa, revisão de Pedro do Nascimento).

11 "Ele rasteja tristemente, feito um cão malfeitor;/ Ela jaz ofegante, com o cansaço de um cordeiro;/ Odiando-se por seu crime, em seus olhos há rancor;/ Com suas unhas, ela rasga a própria carne em desespero; / Ele dali sai pálido, furtivamente em seu medo culposo;/Ela não se move, à noite medonha exclamando;/ Ele corre, seu desaparecido e detestado êxtase censurando./ Um convertido irremediável, ele dali se retira;/ Uma pária sem esperança, ela ali permanece;/ Andando com pressa, ele busca a manhã que ilumina;/ Para esta nunca mais ver, ela faz uma prece;/ "Pois no dia", diz ela, 'não há a escapatória da noite,/ E a verdade de meus olhos nunca se pôs a praticar / Como com uma expressão astuta ofensas ocultar" (SHAKESPEARE. The rape of Lucrece. The Gutemberg Project, tradução nossa, revisão de Pedro do Nascimento).

${ }^{12}$ STAMPLER. The (Un)speakability of Rape: Shakespeare's Lucrece and Lavinia, p. 14. 
homens, ilustrando vários episódios da estória e chamando a atenção para as implicações políticas do tema, como as conhecidas telas de Filippino Lippi e Botticelli. ${ }^{13}$

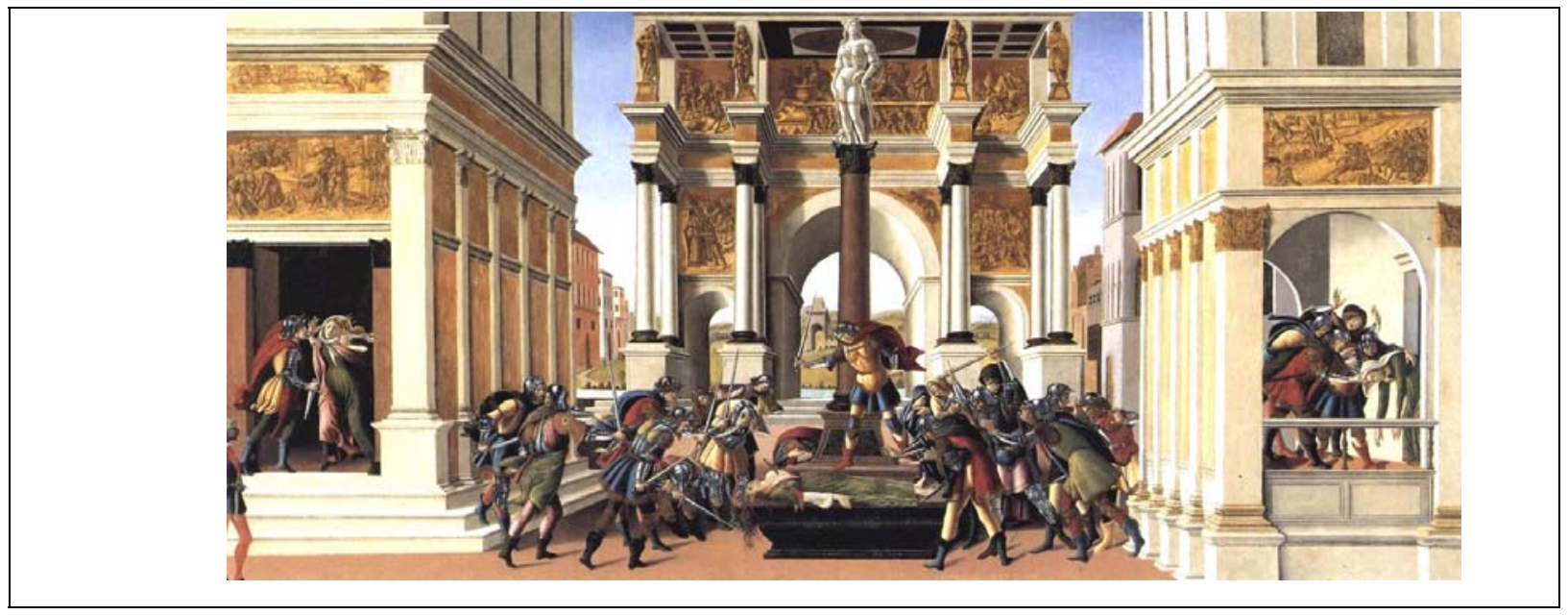

FIG. 1- Sandro Botticelli, História de Lucrécia, c. 1496-1504. Têmpera e óleo sobre madeira, 83,5 por $180 \mathrm{~cm}$. Boston, Isabella, Steward Gardner Museum. Disponível em: <http://www.wga.hu/index1.html>. Acesso em: 9 mar. 2012.

No início do século 16, Lucrécia começa a ser retratada de maneira não casta e até mesmo excessivamente sensual, pressionando o punhal fálico em diversos pontos de seu torso. Lucas Cranach pintou cerca de 35 variações de nu do tipo pin-up. Em algumas das telas, Lucrécia encara o observador de maneira sedutora. ${ }^{14}$

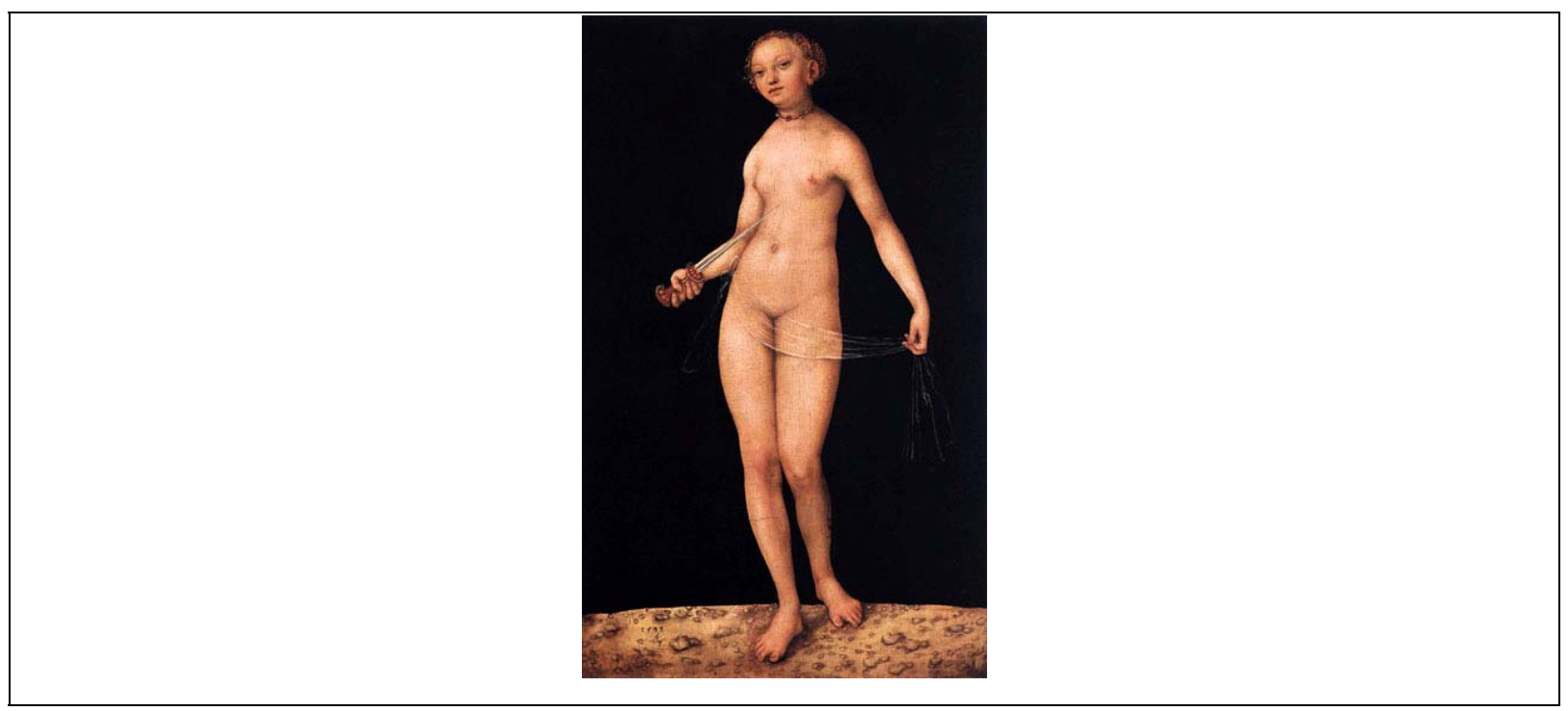

${ }^{13}$ GARRARD. Artemisia Gentileschi: the image of the female hero in Italian baroque art, p. 221.

${ }^{14}$ GARRARD. Artemisia Gentileschi: the image of the female hero in Italian baroque art, p. 223-25 
FIG. 2 - Lucas Cranach, Lucretia, 1533. Tela a óleo, 37 por 24 cm. Berlin-Dahlem, Staaliche Museen. Disponível em: <http://www.wga.hu/index1.html>. Acesso em: 9 mar. 2012.

Outra variação comum na Renascença retrata o ato em uma narrativa pictural dramática. O exemplo mais conhecido é a primeira versão de Ticiano. A tela ganha em literalismo sexual e perde a sugestão pornográfica da versão anterior. A cena é mais próxima da estória original e retrata uma Lucrécia aterrorizada e aflita. ${ }^{15}$

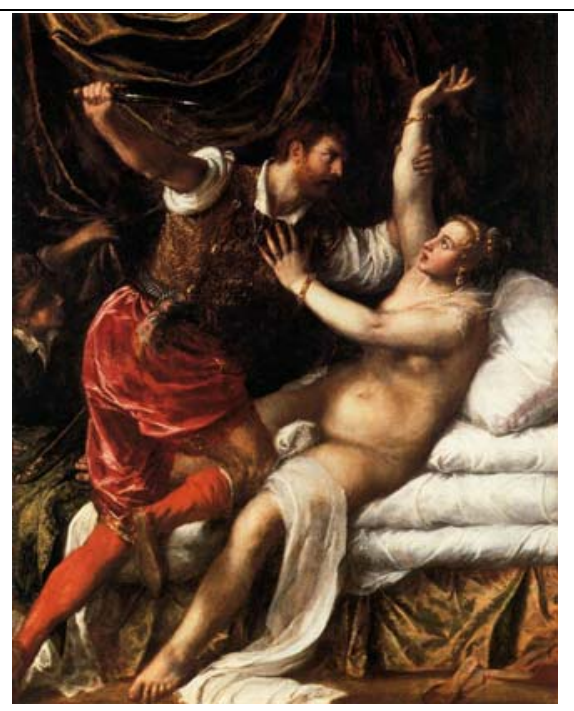

FIG. 3 - Ticiano, Tarquin e Lucrécia, c1570. Tela a óleo, 188,1 por 145,1 cm. Fitzwilliam Museum. Disponível em: <http://www.fitzmuseum.cam.ac.uk/opacdirect/656.html>. Acesso em: 9 mar. 2012.

A Lucretia de Artemísia Gentileschi é datada de 1621, ou seja, menos de três décadas após a publicação do poema de Shakespeare. Ela não é sedutora e nem é uma beldade. Diferentemente de seus contemporâneos, Lucretia ainda não se apunhalou e nem está prestes a fazê-lo. O que a heroína transmite é tensão psicológica e ansiedade emocional por meio da expressão da fronte de seu rosto; da tensão dos ombros e pernas; da firmeza com que agarra o punhal para cima com uma das mãos, e segura o seio com a outra. O seio é o símbolo da continuidade do ciclo da vida, que aqui se contrapõe com o sabre, instrumento que interrompe o ciclo caso ela cometa o suicídio. Essa hesitação, o questionamento de tirar ou não a própria vida, remete ao dilema levantado por Santo Agostinho.

${ }^{15}$ GARRARD. Artemisia Gentileschi: the image of the female hero in Italian baroque art, p. 226. 


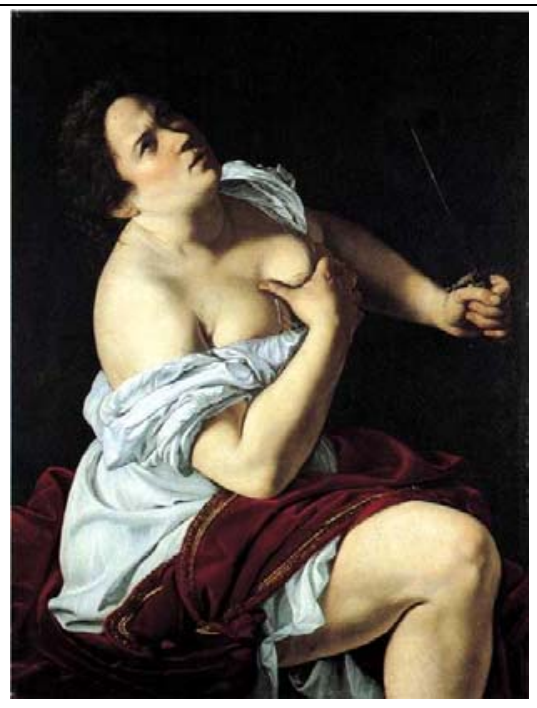

FIG. 4 - Lucretia, c1621. Tela a óleo, 137,16 por 129,54 cm. Palazzo Cattaneo-Adorno, Genova. Disponível em: <http://www.artemisia-gentileschi.com/index.shtml>. Acesso em: 9 mar. 2012.

A pintura barroca italiana é, por essência, narrativa, e um dos objetivos da Igreja Católica era tirar proveito da arte para contar a estória, especialmente da Bíblia, à grande maioria que não podia ler. Segundo a historiadora de arte Svetlana Alpers, a pintura renascentista italiana é um tipo de "superfície ou painel emoldurado a certa distância do observador, que olha através dele para um segundo mundo ou um mundo substituto”. ${ }^{16}$ Esse mundo substituto é como um palco, em que figuras humanas se comportam de acordo com suas fontes de inspiração. Alpers chama isso de "arte narrativa”, na qual a doutrina ut pictura poesis é invocada para explicar e validar imagens por meio de suas relações com textos célebres.

Em acordo com Alpers, a historiadora Mary Garrard faz um paralelo do desconforto de Lucrécia no poema do bardo com o da representada no quadro de Artemísia Gentileschi. Para Garrard, no poema, tanto a vítima quanto seu agressor estão perturbados. Conforme já mencionado, a heroína de Shakespeare pondera tanto valores romanos quanto cristãos e não encontra saída satisfatória, a vergonha causada pelo estupro pede um suicídio honroso, mas tal ato é condenável pela moral cristã. ${ }^{17}$ Os recortes a seguir ilustram sua luta para resolver esse conflito de prioridade:

"To kill myself," quoth she, "alack, what were it,/ But with my body my poor soul's pollution? (...) 'My body or my soul, which was the dearer,/

${ }^{16}$ ALPERS. A arte de descrever: a arte holandesa no século XVII, p. 27.

${ }^{17}$ GARRARD. Artemisia Gentileschi: the image of the female hero in Italian baroque art, p. 228-237. 
When the one pure, the other made divine?/ Whose love of either to myself was nearer,/ When both were kept for heaven and Collatine? ${ }^{18}$

Teria sua alma sido tão poluída quanto seu corpo? Lucrécia lamenta que esteja despojada de seu corpo e de sua alma, uma vez que ambos foram mantidos para o céu e para o marido. De acordo com Garrard, nenhuma outra personagem feminina de Shakespeare apresenta dilema com tamanho peso psíquico, que é comparável ao de Hamlet ou Lear. Tanto a Lucretia da pintora Artemísia quanto a Lucrécia, personagem de Shakespeare, demonstram uma inquietação consciente em relação à decisão a ser tomada. ${ }^{19}$ Contudo, apesar de toda a sua ponderação, a Lucrécia de Shakespeare opta por seguir as leis de Roma, e não os valores cristãos. Para ela, como suas precursoras, a única saída é o mesmo suicídio: “This helpless smoke of words doth me no right./ The remedy indeed to do me good/ Is to let forth my fouldefil'd blood."20

A representação de Artemísia Gentisleschi nas artes é tão incomum quanto à de Shakespeare na literatura.

De acordo com Elizabeth Cohen, o evento do estupro de Artemísia Gentileschi, assim como o julgamento de seu tutor Agostino Tassi, tornaram-se tema central na literatura a respeito da pintora na virada do século 21. A interpretação de sua obra recai nesse violento e traumático evento, e as imagens de sexo, violência e vulnerabilidade feminina são traços característicos da obra de Gentileschi. ${ }^{21}$ A autora do romance Susan Vreeland afirma, em seu site na internet, que o romance, escrito no século 21, teve como inspiração os registros do julgamento de Agostino Tassi encontrados na obra de Mary Garrard e na obra pictórica da pintora Artemísia Gentileschi. A autora faz vasto uso do recurso literário ecfrase para costurar a trama. Shakespeare também faz uso de tal recurso no poema, quando Lucrécia descreve uma tapeçaria com o tema da Guerra de Troia ao ponderar como irá se matar. Nesse trecho ecfrástico, ela compara a sua dor ao desespero de Hécuba. E quando menciona Helen’s rape,

18 “'Para me matar’, disse ela, 'faltasse, o que fosse,/ Senão meu corpo, a sujeira de minha alma?/ "Meu corpo ou meu espírito, com qual mais me afeiçoava/ Sendo um puro, e o outro divino?/ Qual amor próximo de mim mais deixava,/ Quando os dois guardava aos céus e Colatino?" (SHAKESPEARE. The rape of Lucrece. The Gutemberg Project, tradução nossa, revisão de Pedro do Nascimento).

${ }^{19}$ GARRARD. Artemisia Gentileschi: the image of the female hero in Italian baroque art, p. 238.

20 "Esta impotente fumaça de palavras não me traz bem./ Para o meu alívio, de fato a solução/ É o derrame de meu sangue, marcado pela corrupção" (SHAKESPEARE. The rape of Lucrece. The Gutemberg Project, tradução nossa, revisão de Pedro do Nascimento).

${ }^{21}$ COHEN. The trials of Artemisia Gentileschi: a rape as history, p. 47. 
está se referindo ao rapto, e não ao estupro, de Helena, confirmando o duplo sentido da palavra.

No romance A paixão de Artemísia, a protagonista está vivendo um momento singular em sua vida na casa do patrono Cesare Gentile, em Genova. Ele acredita no talento da artista e a deixa à vontade para escolher os temas de suas pinturas. Além disso, as filhas dos Gentile fazem companhia a sua filha Palmira, que passa o dia brincando pelo palácio. Pela primeira vez, Artemísia tem tempo para se dedicar à sua arte como sempre sonhou. Porém, essa zona de conforto é quebrada quando Gentile a encomenda uma pintura representativa do mito de Lucrécia, para que suas filhas temam a perda da castidade. A princípio, a protagonista se nega a pintar uma mulher que se matou de vergonha, mas o patrono a sugere que ela encare essa comissão como um desafio. Artemísia alega detestar "todos os quadros que mostram Lucrézia morta, numa serena virtude, o rosto mostrando uma paz que o pintor sentiu, não ela. Não é assim que fica um suicida”. ${ }^{22}$ Essa fala da protagonista me aponta uma tendência de valores que estão mais de acordo com os cristãos do que com as leis de Roma. Artemísia continua seu raciocínio e menciona a

versão feita por Filippino Lippi que está no palazzo Pitti, em Florença, [em que Lucrézia] se mata em público. Para [Artemísia], essa é a suprema maluquice. Se era inocente, não precisava se envergonhar. Matar-se foi um ato orgulhoso e insensato, mas não enobrecedor. Uma saída que pode ter parecido interessante por um instante, mas... quem ama a vida não busca essa saída. ${ }^{23}$

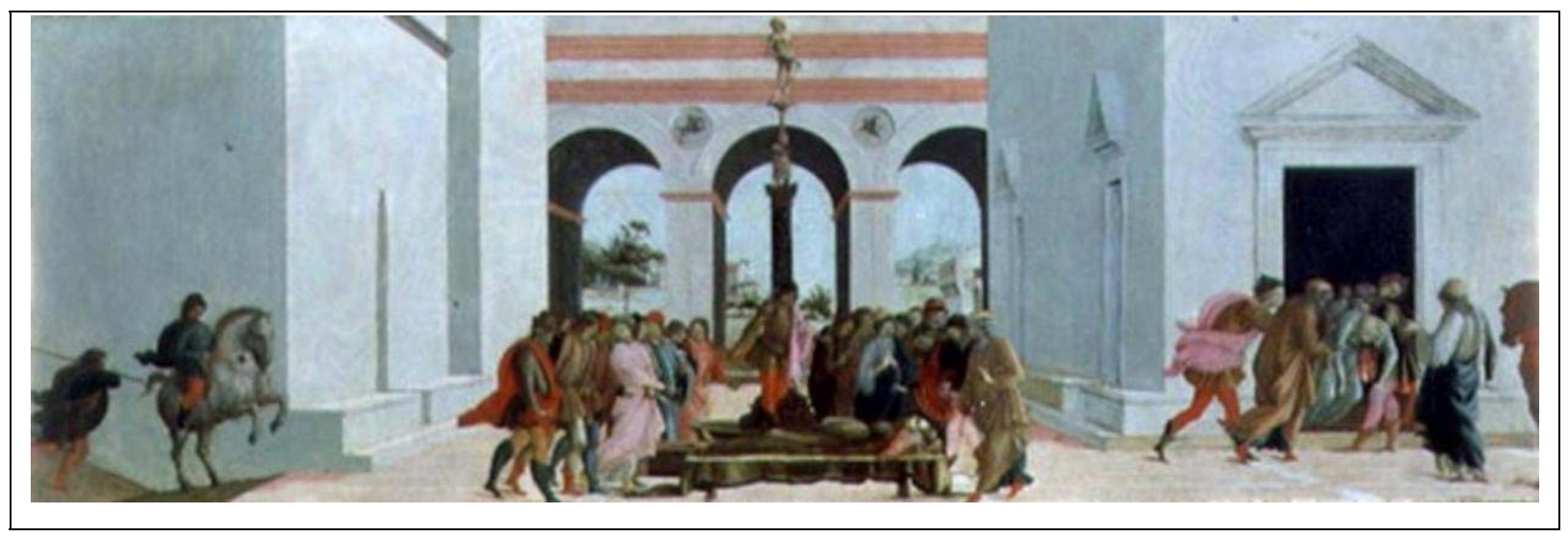

FIG. 5 - Fillippino Lippi, A morte de Lucrécia, c. 1457-1504. Têmpera sobre madeira. Coleção particular, Freiburg. Disponível em:

<http://it.wikipedia.org/wiki/File:Filippino,_morte_di_lucrezia.JPG>. Acesso em: 9 mar. 2012.

\footnotetext{
${ }^{22}$ VREELAND. A paixão de Artemísia, p. 217.

${ }^{23}$ VREELAND. A paixão de Artemísia, p. 217.
} 
Aqui ressoa a voz da autora americana, que, ao fazer o inevitável paralelo entre a simbologia do mito de Lucrécia na pintura e a reação da protagonista ao seu próprio estupro, nos mostra uma maior valorização da mulher e da vida, valores difundidos no século 21 . No entanto, a protagonista reforça a visão machista do crime, ainda comum hoje em dia, quando afirma que existe a possibilidade de "que as vítimas sintam a mesma culpa ou até provoquem o estupro,” e contrapõe o argumento alegando que "Lucrézia só faz sentido para os que acham que as mulheres gostam de ser violentadas”. O comentário a respeito de Lucrécia ser "uma mártir falsa e inútil”24 está em acordo com a visão da escritora italiana Lucrezia Marinelli (1572-1653), contemporânea da pintora Artemísia Gentileschi. A protagonista do romance conclui que prefere retratar suas ideias, e não as do mito, em sua versão, mostrando “dois caminhos: a vida e a maternidade versus o suicídio e o martírio.”25 Essa oscilação de valores me soa como intencional por parte da autora para promover uma maior identificação de seu público com a protagonista. Uma fragilizada e sofrida mártir, nos moldes de Lívio e Ovídio, provavelmente não venderia tantos livros.

Durante a execução da pintura, a protagonista tem um bloqueio na hora de pintar o punhal. Assim como a Lucrécia, personagem de Shakespeare, a Artemísia, protagonista de Vreeland, passa por momentos de hesitação. Ela decide terminar o rosto, retratando a figura do mito como uma Lucrécia inquieta e inquietante. Mas o olhar "perturbado e penetrante e a mão apenas esboçada, segurando o punhal sobre o seio, pareciam errados... [a] mão [da pintora] estava paralisada”. ${ }^{26}$ Então, a protagonista, que é também a narradora, pede que a figura do mito Lucrécia fale com ela, e então “escuta” pelos olhos de sua obra que ela deveria se lembrar. A protagonista revive então o momento em que ela foi torturada durante o julgamento de seu agressor. Naquele dia, apesar de não pegar o punhal debaixo de sua cama, pensou em fazê-lo. E depois de questionar se a mártir estaria realmente sem saída, decide não retratar o momento em que Lucrécia vai se matar, e sim, o momento anterior em que "ela não vai fazer nada, apenas pensar, refletir sobre o que o mundo lhe ensinou, questionar o sacrifício, mas sem a intenção de se matar”. ${ }^{27}$

No dia da grande apresentação do quadro, o pai de Artemísia, Orazio Gentileschi, é o primeiro a vê-lo. Sua primeira impressão é que Lucrécia está com medo, mas Artemísia

\footnotetext{
${ }^{24}$ VREELAND. A paixão de Artemísia, p. 217.

${ }^{25}$ VREELAND. A paixão de Artemísia, p. 217-222.

${ }^{26}$ VREELAND. A paixão de Artemísia, p. 224.

${ }^{27}$ VREELAND. A paixão de Artemísia, p. 225.
} 
retruca e diz que é inquietação. Ele alega que aquela "não é a Lucrézia que todos imaginam”. ${ }^{28} \mathrm{E}$ a protagonista explica ao pai que

... ela tem que ser assim, insegura; dessa forma, quem olhar o quadro daqui a muito tempo, mulheres e homens também, vai sentir um mal-estar, talvez cheguem a chorar ao pensar que, num tempo de ignorância, houve uma mulher que foi forçada a se suicidar por ter sido violentada. Até se esperava que ela fizesse isso... as coisas vão mudar... precisam mudar. E a arte pode ajudar nessa mudança. ${ }^{29}$

Expressando a sua própria reação ao estupro, Artemísia quer deixar claro para o pai, e para o leitor, que ela está à frente de seu tempo.

Finalmente, na festa de apresentação da tela para os convidados dos Gentile, todos ficam surpresos, pois esperavam sangue e a pintora lhes ofereceu a dúvida. O patrono gosta do resultado e diz que "se o tempo parasse no momento em que [Artemísia] retratou Lucrézia, jamais saberíamos o que ela fez" ${ }^{30}$ Essa mudança de paradigma do mito de Lucrécia pode ser observada na hesitante Lucretia de Artemísia Gentileschi, pintado no século 17, mas que ganha força pela voz da protagonista narradora de Vreeland no século 21.

Ao contrário da hesitante Lucrécia, heroína do poema de Shakespeare, o suicídio não é a única saída honrosa para a vítima do estupro. A pintora Artemísia Gentileschi não se matou. A obra da pintora caravaggista é repleta de momentos em que ela parece curar sua dor por meio de sua arte, como na sua inusitada representação em tela de uma inquieta Lucretia. A tormenta mental sugerida pela pintura aparece também nos versos de Shakespeare, a Lucretia do quadro e Lucrécia do poema carregam uma ambiguidade singular para os padrões de releitura do mito daquela época. Ao mesclar fatos históricos com a ficção, o romance de Vreeland pincela as questões do dilema do estupro com um olhar contemporâneo, para assim atender seu público. Mas foi a contribuição não datada de Shakespeare com o poema O Rapto de Lucrécia que me instigou a ler a pintura Lucretia e ouvir o mito de Lucrécia no romance sob uma nova perspectiva, oferecendo-me uma maior compreensão em relação à maneira de lidar com a violação sexual da protagonista narradora do meu objeto de estudo, Artemísia.

\footnotetext{
${ }^{28}$ VREELAND. A paixão de Artemísia, p. 228.

${ }^{29}$ VREELAND. A paixão de Artemísia, p. 228.

${ }^{30}$ VREELAND. A paixão de Artemísia, p. 230.
} 


\begin{abstract}
This essay aims to search for evidence on ways of coping with sexual violation in the depiction of the female protagonists of the chapter “Lucrezia” by Susan Vreeland (2002); of the painting Lucretia by Artemisia Gentileschi (1621), and of the narrative poem The rape of Lucrece by Shakespeare (1594).
\end{abstract}

\title{
KEYWORDS
}

Intermidialidade, literature, painting

\section{REFERÊNCIAS}

ALPERS, Svetlana. A arte de descrever: a arte holandesa no século XVII. Trad. Antônio de Pádua Danesi. São Paulo: Edusp, 1999.

BAL, Mieke. The Artemisia files: Artemisia Gentileschi for feminists and other thinking people. Chicago: U of Chicago P, 2005.

BELSEY, Catherine. Tarquin dispossessed: expropriation and consent. In: BELSEY, Catherine (Ed.). The rape of Lucrece: Shakespeare in theory and practice. Edinburgh: Edinburgh UP, 2008. p. 54-72.

BOWEN, Barbara E. The rape of Jesus: Aemilia Lanyer's Lucrece. In: HOWARD, Jean E.; SHERSHOW, Cutler (Ed.). Marxist Shakespeares. London/New York: Routledge, 2001. p. 106-125.

HOUAISS, Antonio; VILLAR, Mauro de Salles. Dicionário Houaiss da língua portuguesa. Rio de Janeiro: Objetiva, 2009.

DICTIONARY.COM. "RAPE.” In: Online Etymology Dictionary. Fonte: Douglas Harper, Historian. Disponível em: <http://dictionary.reference.com/browse/rape>. Acesso em: 3 dez. 2011.

COHEN, Elizabeth. The trials of Artemisia Gentileschi: a rape as history. Sixteenth Century Journal 30, n. 1, p. 47-75, 2000.

GARRARD, Mary D. Artemisia Gentileschi: the image of the female hero in Italian baroque Art. Princeton, NJ: Princeton UP, 1989.

GOMES, Luiz Flávio. Violência machista universal: 11 mulheres são assassinadas por dia no Brasil. Violência de gênero. Disponível em $<$ http://atualidadesdodireito.com.br/violenciadegenero/2011/12/02/violencia-machistauniversal-11-mulheres-sao-assassinadas-por-dia-no-brasil/> . Acesso em: 7 dez. 2011.

HONAN, Park. Shakespeare: uma vida. Trad. Sônia Moreira. São Paulo: Companhia das Letras, 2001.

O GLOBO. Afegã é perdoada, mas terá que se casar com homem que a estuprou, 1 dez. 2011. Disponível em: <http://oglobo.globo.com/mundo/afega-perdoada-mas-tera-que-se-casar-comhomem-que-estuprou-3363221\#ixzz1fwSqJTp5>. Acesso em: 7 dez. 2011. 
OLIVEIRA, Solange Ribeiro de. Contemporaneidade de Shakespeare: a violência contra a mulher no poema narrativo $O$ estupro de Lucrécia. Disponível em: $<$ http://www.letras.ufmg.br/poslit/16_producao_pgs/OLIVEIRA,\%20Solange.Contemporanei dade.2008.pdf $>$. Acesso em: 28 nov. 2011.

PARKER, Christine. The life and art of Artemisia Gentileschi. Disponível em: <http://www.artemisia-gentileschi.com/index.shtml >. Acesso em: 25 jun. 2011.

RUBIN, Alissa J. Controverso perdão a vítima de estupro expõe drama das afegãs. Times, New York, 3 dez. 2011. Disponível em: <http://oglobo.globo.com/mundo/controversoperdao-vitima-de-estupro-expoe-drama-das-afegas-3373574>. Acesso em: $7 \mathrm{dez} .2011$.

SHAKESPEARE. The rape of Lucrece. The Gutemberg Project. [0]Disponível em: <http://www.gutenberg.org/cache/epub/1505/pg1505.html>. Acesso em: 2 dez. 2011.

STAMPLER, Laura. The (Un)speakability of Rape: Shakespeare's Lucrece and Lavinia. English Honors Thesis. Stanford University, Califórnia, 2010. Disponível em: $<$ http://pt.scribd.com/doc/32440195/The-Un-speakability-of-Rape-Shakespeare-s-Lucreceand-Lavinia>. Acesso em: 26 nov. 2011.

VREELAND, Susan. A paixão de Artemísia. Trad. Beatriz Horta. Rio de Janeiro: José Olympio, 2010.

VREELAND, Susan. The passion of Artemisia. New York: Penguin Books, 2003.

VREELAND, Susan. The passion of Artemisia: the genesis of the book. Disponível em: $<$ http://www.svreeland.com/gen-art.html>. Acesso em: 30 nov. 2011. 